\title{
Coulisses
}

Revue de théâtre

7| Printemps 1993

Varia

\section{Un spectacle pour l'Europe : Cymbelin d'après Shakespeare}

\section{OpenEdition}

Journals

Édition électronique

URL : http://journals.openedition.org/coulisses/2254

DOI : $10.4000 /$ coulisses.2254

ISSN : 2546-9460

Éditeur

Presses universitaires de Franche-Comté

\section{Édition imprimée}

Date de publication : 1 avril 1993

Pagination : 36-38

ISSN : $1150-594 X$

Référence électronique

"Un spectacle pour l'Europe: Cymbelin d'après Shakespeare », Coulisses [En ligne], 7 | Printemps 1993, mis en ligne le 15 mars 2019, consulté le 31 octobre 2019. URL : http://journals.openedition.org/ coulisses/2254; DOI : 10.4000/coulisses.2254

Ce document a été généré automatiquement le 31 octobre 2019

Coulisses 


\section{Un spectacle pour l'Europe : Cymbelin d'après Shakespeare}

Une co-production internationale de huit théâtres universitaires en l'honneur de l'Europe de 1993.

90 étudiants -5 langues

Drame volontairement optimiste en trois Actes avec Prologue et Epilogue.

Avec les Théâtres Universitaires de :

Franche-Comté, Dijon, Liège, Glasgow, Edimburgh, Urbino, Iasi (Roumanie), Vilnius (Lituanie)

Metteur en scène-coordinateur : François RoDINSON 


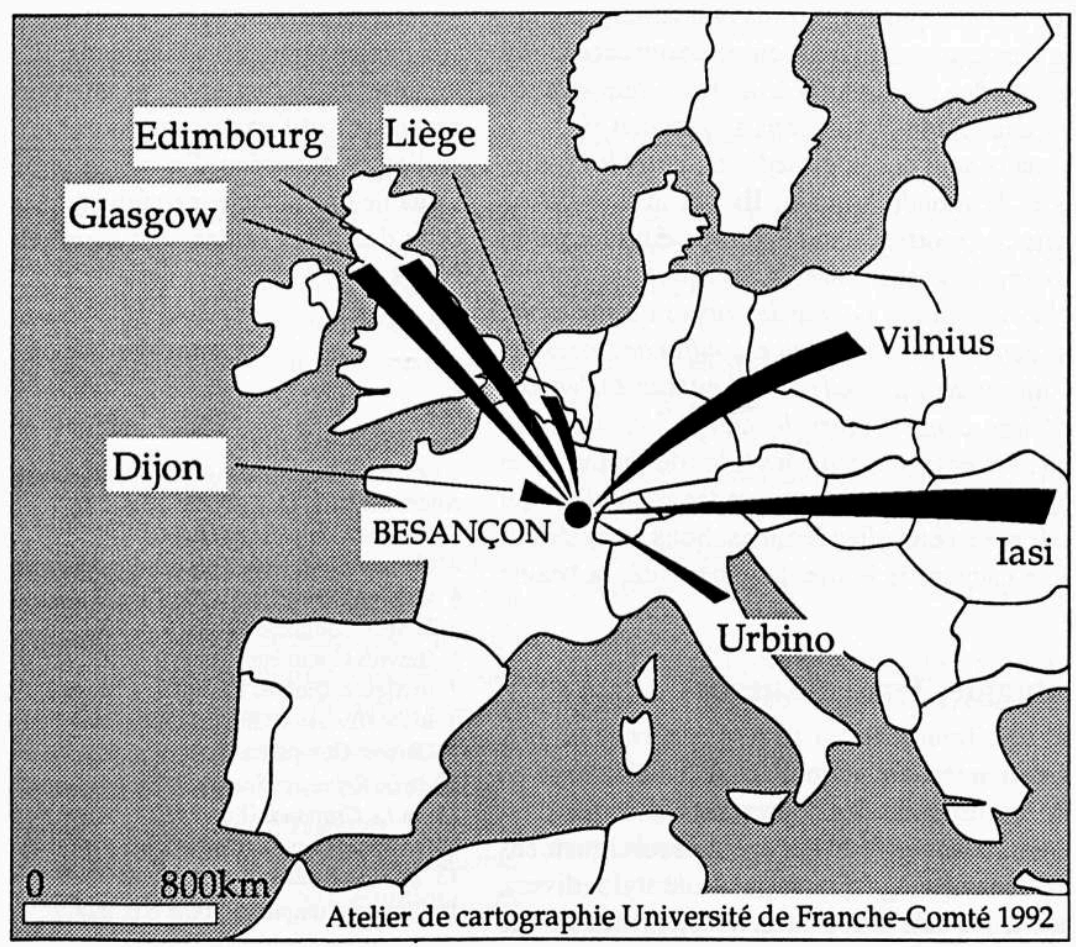

\section{Prologue ou l'origine du projet : un désir exigeant}

Depuis sa création en octobre 1986, le Théâtre Universitaire de Franche-Comté, s'est donné comme mission la production dramatique et la diffusion de la culture théâtrale en milieu universitaire. Il a ainsi créé une quinzaine de spectacles, participé à de nombreux festivals de théâtre universitaire, organisé un colloque, trois Rencontres Internationales Théâtre et Université où se sont confrontés universitaires, écrivains, professionnels du spectacle vivant, et théâtres universitaires. Ces expériences ont suscité un désir plus exigeant: travailler ensemble à un spectacle commun en l'honneur d'un événement qui nous concerne tous: l'ouverture des frontières européennes.

\section{Acte I : Exposition/préparation}

\section{Travailler ensemble ? pour quoi ? avec qui ? sur quoi ? comment ?}

Pour répondre à ces questions des stages ont été organisés les 21-25 avril et du 3 au 22 août 1992 pour une mise en commun des propositions de mise en scène.

\section{Pour quoi ?}

Travailler ensemble à une production commune suppose que les différences ethniques, esthétiques, linguistiques deviennent un levier pour une quête commune de la vérité à la fois propre à chacun et au groupe dans son ensemble, plus prosaïquement d'une méthode capable de susciter les émotions qui dépassent les frontières. 


\section{Avec qui ?}

Les théâtres universitaires ont été contactés directement ou indirectement, ceux de Dijon, Urbino, Liège, Edimburgh, Iasi, Glasgow, et Vilnius sont devenus partie prenante du projet. La nécessité $d$ 'avoir un coordinateur-metteur-en-scène qui gère l'ensemble de la création collective s'est imposée et le Centre Dramatique National de Franche-Comté a proposé un assistant de René Loyon, François Rodinson.

\section{Sur quoi ?}

Pour des raisons multiples, il est apparu plus simple de travailler sur un texte déjà publié et traduit. François Rodinson a proposé cymbelin, drame méconnu de la fin de la vie de Shakespeare qu'on peut lire comme une synthèse de son œuvre, au travers de multiples intrigues enchevêtrées, comme l'histoire des affrontements inter-personnels et européens, dans une dynamique où finalement l'emportent la raison et la paix.

\section{Comment ?}

Après avoir élaboré au cours du stage du mois d'août 92 , un synopsis commun et sa partition propre, chaque théâtre universitaire va travailler à la création du spectacle de Cymbelin durant l'année 1992-1993.

\section{Acte II : La réalisation}

Pendant l'année 92-93 chaque théâtre universitaire travaille sur sa partie, et sa participation financière à l'ensemble du projet.

Du 10 au 20 juillet 1993 à Besançon : Répétitions

21 juillet 1993 : Première à Besançon de ce spectacle européen exceptionnel dans le cadre des IV èmes Rencontres Internationales Théâtre et Université

\section{Acte III : La diffusion ; les retombées}

A compter du 23 juillet: diffusion de la création dans les FESTIVALS des villes universitaires concernées.

23-24-25 juillet : Estivades de Dijon

30 juillet : Teatrorizzonti d'Urbino

Festival de la Jeunesse à Constanta, Festival de Vilnius, Festival International d'Edinburgh.

Février $94: 11^{\text {ème }}$ Rencontre Internationale des Théâtres Universitaires de Liège.

Les participants sont accueillis dans le cadre des cités et restaurants universitaires.

\section{Epilogue}

A l'instar de cymbelin, l'épilogue de notre spectacle devrait être heureux c'est-à-dire une création riche de ses huit théâtres universitaires, de sa centaine d'étudiants, de leurs différences harmonisées pour un spectacle qui parle de guerre et de paix, d'ambition et de haine, d'amour et de sérénité acquise. 
La création de Cymbelin c'est : traduire cette pièce en lituanien, créer un festival de théâtre à Urbino, publier un numéro spécial COULISSES.

Le projet est inscrit comme module optionnel des cours d'été du Centre Linguistique Appliquée de Besançon : «Approches d'un projet culturel étudiant international ». Il a été retenu comme sujet de communication au Colloque International de l'Université Libre de Bruxelles en mars 1993 et à celui de l'Association Interuniversitaire de l'Est en décembre 1993. 